Portland State University

PDXScholar

Environmental Science and Management

Faculty Publications and Presentations

$1-2011$

\title{
Direct and Indirect Effects of an Invasive Planktonic Predator on Pelagic Food Webs
}

\author{
Angela L. Strecker \\ Portland State University, angela.strecker@wwu.edu \\ Beatrix E. Beisner \\ University of Quebec at Montréal \\ Shelley E. Arnott \\ Queen's University - Kingston, Ontario \\ Andrew M. Paterson \\ Dorset Environmental Science Centre \\ Jennifer G. Winter \\ Ontario Ministry of the Environment
}

See next page for additional authors

Follow this and additional works at: https://pdxscholar.library.pdx.edu/esm_fac

Part of the Fresh Water Studies Commons, Marine Biology Commons, and the Oceanography

Commons

Let us know how access to this document benefits you.

\section{Citation Details}

Strecker, A.L., B.E. Beisner, S.E. Arnott, A.M. Paterson, J. Winter, O.E. Johannsson, and N.D. Yan. 2011. Direct and indirect effects of an invasive planktonic predator on pelagic food webs. Limnology and Oceanography 56: 179-192.

This Article is brought to you for free and open access. It has been accepted for inclusion in Environmental Science and Management Faculty Publications and Presentations by an authorized administrator of PDXScholar. Please contact us if we can make this document more accessible: pdxscholar@pdx.edu. 


\section{Authors}

Angela L. Strecker, Beatrix E. Beisner, Shelley E. Arnott, Andrew M. Paterson, Jennifer G. Winter, Ora E. Johannsson, and Norman D. Yan

This article is available at PDXScholar: https://pdxscholar.library.pdx.edu/esm_fac/38 


\title{
Direct and indirect effects of an invasive planktonic predator on pelagic food webs
}

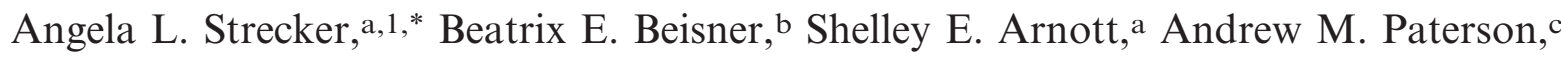 \\ Jennifer G. Winter, ${ }^{\mathrm{d}}$ Ora E. Johannsson, ${ }^{\mathrm{e}}$ and Norman D. Yan ${ }^{\mathrm{f}}$ \\ a Department of Biology, Queen's University, Kingston, Ontario, Canada \\ b Department of Biological Sciences, University of Quebec at Montréal, Montréal, Québec, Canada \\ c Ontario Ministry of the Environment, Dorset Environmental Science Centre, Dorset, Ontario, Canada \\ dOntario Ministry of the Environment, Water Monitoring Section, Toronto, Ontario, Canada \\ e Department of Fisheries and Oceans Canada, Canadian Centre for Inland Waters, Burlington, Ontario, Canada \\ f Department of Biology, York University, Toronto, Ontario, Canada
}

\begin{abstract}
The relative importance of top-down invader effects relative to environmental drivers was determined by sampling crustacean zooplankton, rotifer, and phytoplankton communities in a set of invaded and noninvaded reference lakes. The non-native invertebrate predator Bythotrephes had significant effects on zooplankton community size structure, rotifers, and phytoplankton taxonomic composition, but no significant effects on crustacean zooplankton taxonomic and functional group composition. Part of the variation in phytoplankton communities was explained by the presence of the invader. Because Bythotrephes is generally known to be a carnivore and to not consume phytoplankton, this effect is likely mediated by the zooplankton community's response to environmental gradients. Although Bythotrephes appears to indirectly alter phytoplankton composition in invaded lakes, there was no evidence of a trophic cascade, and edible phytoplankton biovolume did not increase in invaded lakes. These complex direct and indirect interactions suggest that effects of invaders may be highly context-dependent, and therefore pose a significant challenge for predicting wider community and ecosystem responses.
\end{abstract}

Cascading effects of predators are common in aquatic systems and may be more noticeable following the introduction of novel predators (Carpenter et al. 1987; McCann et al. 1998). Range expansion of invasive predators can provide natural experiments with which to examine altered interactions among trophic levels at the whole-ecosystem scale. In terrestrial ecosystems, invasive predators have larger effects on prey communities compared to native predators (Salo et al. 2007), but their cascading effects have rarely been explored in aquatic ecosystems. The consequences of invasions for nonadjacent lower trophic levels remain largely unexplored and are difficult to predict because there can be large variation in the strength of top-down effects among lake ecosystems (Shurin et al. 2002). In particular, oligotrophic lakes are more likely to show weak top-down effects at lower trophic levels because of strong bottom-up forces (McQueen et al. 1986; Leibold et al. 1997; Jeppesen et al. 2003).

It has been suggested that mid-trophic-level invaders may have disproportionately large effects on food webs (Shuter and Mason 2001; Noonburg and Byers 2005). The cladoceran zooplankter Bythotrephes longimanus is an invasive predator in North America, where it occupies a mid-trophic-level position in lakes. It has had large effects on pelagic herbivore community structure, biomass, and productivity in North American lakes (Yan et al. 2002; Boudreau and Yan 2003; Strecker and Arnott 2008). Based

\footnotetext{
*Corresponding author: angelast@u.washington.edu

${ }^{1}$ Present address: School of Aquatic and Fishery Sciences, University of Washington, Seattle, Washington
}

on the strong effects of this invader on herbivorous zooplankton, we would expect to see strong cascading effects on lower trophic levels, including changes in taxonomic composition, size, and structure, and functional group composition in the phytoplankton. However, $B y$ thotrephes is most commonly found in low-productivity lakes (MacIsaac et al. 2000). Thus, it is unclear whether cascading effects of the invader should attenuate rapidly or be expressed with equal strength at the lower trophic level.

The rapid invasion of Bythotrephes into a large set of morphologically and chemically similar lakes in central Ontario created a unique opportunity to analyze replicated natural, whole-lake experiments on lower food web responses to invasion. Although previous studies have demonstrated strong effects of Bythotrephes on the adjacent trophic level (zooplankton: Barbiero and Tuchman 2004; Hovius et al. 2006; Strecker et al. 2006), the effect on primary producers has remained largely unexplored. To our knowledge, no studies have examined the effects of Bythotrephes on phytoplankton community composition, although an experimental mesocosm study did demonstrate increases in phytoplankton abundance with invasion, suggestive of a trophic cascade (Strecker and Arnott 2005). Furthermore, the contribution of Bythotrephes in shaping plankton communities relative to the role of other important environmental drivers (Watson et al. 1997; Beisner et al. 2006; Keller 2009) is not well understood. Based on food web theory, one might expect that herbivorous zooplankton should be more affected by top-down influences, whereas phytoplankton communities, being lower in the food chain, should be shaped more strongly by bottom-up effects (McQueen et al. 1986). 


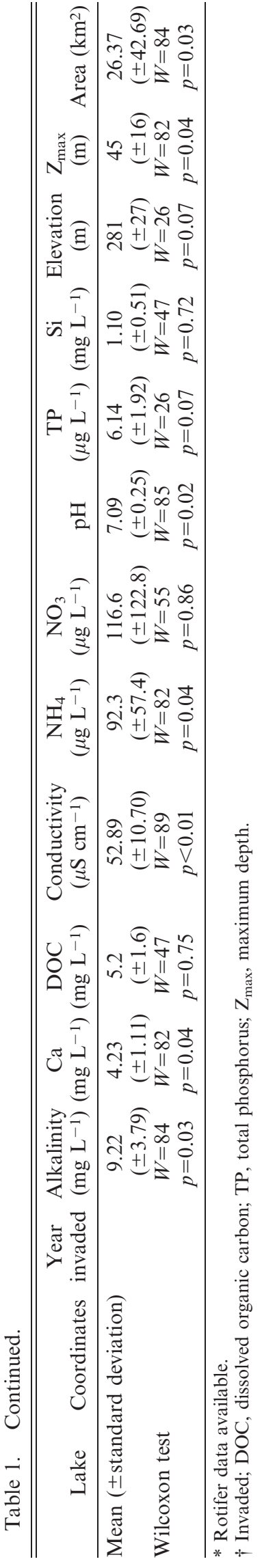

Indeed, this pattern has been recently demonstrated in comparative studies of boreal shield lakes (Paterson et al. 2008).

Our objective was to assess whether Bythotrephes induces patterns in planktonic food webs that are indicative of a trophic cascade. Further, we were interested in determining if trophic cascades would manifest in the traditional form (e.g., changes in phytoplankton biomass) or in a more subtle form (e.g., shifts in phytoplankton composition). We accomplished this by contrasting phytoplankton, rotifer, and zooplankton community structure in invaded and noninvaded lakes in a region of rapid range expansion of the invader. This was done by surveying a relatively large set of lakes at multiple times throughout the summer. We predicted that traditional trophic cascades would be weak or absent in the low-productivity lakes that are characteristically invaded by Bythotrephes (MacIsaac et al. 2000), because phytoplankton would be more strongly influenced by environmental factors, but that more subtle cascades may result from indirect effects of Bythotrephes on the zooplankton community.

\section{Methods}

Sampling-Twenty-two lakes in the districts of Muskoka and Parry Sound, and the county of Haliburton in Ontario, Canada, were sampled from May to September 2003. There were 15 invaded and 7 reference lakes, including the recently invaded Maple Lake, which was classified in our study as a reference system, since only one Bythotrephes individual was found throughout the summer. Two of our noninvaded reference lakes are part of a long-term monitoring program; sampling details can be found in Paterson et al. (2008) and Yan et al. (2008).

All of the lakes chosen for the study have relatively similar physical, chemical, and morphological characteristics (Table 1); however, there were some differences between lake categories (assessed with a nonparametric Wilcoxon rank test). Invaded lakes tended to have higher alkalinity, calcium, conductivity, $\mathrm{NH}_{4}, \mathrm{pH}$, and sodium (not shown), and were deeper and larger (Table 1). These differences were generally small, as would be expected from lakes located in a geologically similar region, and are typical of the broader patterns of invasion in the region (Weisz and Yan 2010). The morphological differences in invaded lakes compared to noninvaded lakes may reflect Bythotrephes preference for large deep lakes (MacIsaac et al. 2000), but it is more likely an artifact of the recent history of invasions in North America. The spread of Bythotrephes is largely controlled by human-delivered propagules, and propagule pressure is higher in larger lakes (Muirhead and MacIsaac 2005). Lake depth is known to influence zooplankton community structure, primarily because deeper lakes are more likely to contain glacial relict species, such as Mysis relicta and Senecella calanoides (Dadswell 1974), which are zooplankton predators. However, we purposely chose lakes with a common glacial history (with the exception of two reference lakes, Blue Chalk and Red Chalk Main, for which preliminary analyses indicated that zooplankton communities did not 
Table 2. Functional classification of crustacean zooplankton following Barnett et al. (2007). Group 1 represents smaller herbivores (both cladocerans and copepods), group 2 represents larger carnivore to omnivore taxa (copepods and the predaceous Polyphemus pediculus), group 3 represents pelagic filter-feeding larger cladocerans (most Daphnia species), group 4 represents pond and/or littoral large cladocerans (e.g., Daphnia pulex), and group 5 represents midsized filter-feeding cladocerans (e.g., Diaphanosoma birgei).

\begin{tabular}{|c|c|}
\hline Species & Functional classification \\
\hline Acanthocyclops robustus & 2 \\
\hline Acroperus harpae & 1 \\
\hline Bosmina spp. & 1 \\
\hline Chydorus brevilabris & 1 \\
\hline Cyclops scutifer & 2 \\
\hline Daphnia ambigua & 3 \\
\hline Daphnia catawba & 3 \\
\hline Daphnia dubia & 3 \\
\hline Daphnia galeata mendotae & 3 \\
\hline Daphnia longiremis & 3 \\
\hline Daphnia pulex & 4 \\
\hline Daphnia retrocurva & 3 \\
\hline Diacyclops bicuspidatus thomasi & 2 \\
\hline Diaphanosoma birgei & 5 \\
\hline Epischura lacustris & 2 \\
\hline Eubosmina coregoni & 1 \\
\hline Eubosmina tubicen & 1 \\
\hline Holopedium glacialis & 3 \\
\hline Latona setifera & 5 \\
\hline Leptodiaptomus ashlandi & 1 \\
\hline Leptodiaptomus minutus & 2 \\
\hline Leptodiaptomus sicilis & 1 \\
\hline Limnocalanus macrurus & 2 \\
\hline Macrocyclops albidus & 2 \\
\hline Mesocyclops edax & 2 \\
\hline Orthocyclops modestus & 2 \\
\hline Polyphemus pediculus & 2 \\
\hline Senecella calanoides & 1 \\
\hline Sida crystallina & 4 \\
\hline Skistodiaptomus oregonensis & 2 \\
\hline Tropocyclops extensus & 1 \\
\hline
\end{tabular}

differ substantially from the other reference lakes; A. Strecker unpubl.). Thus, lake size likely did not confound our interpretation of responses of the crustacean zooplankton community to Bythotrephes invasion. Furthermore, lake size per se is not expected to have a major influence on phytoplankton or rotifer community structure, independent of its effects on temperature and stratification type (Wetzel 2001). Summer epilimnetic temperatures and depths were similar in both invaded and noninvaded lakes (July and August: A. Strecker unpubl.); therefore, differences in lake size likely did not affect our interpretation of invasion effects on phytoplankton or rotifer community structure. Lakes contained a combination of warm-water planktivores (e.g., yellow perch [Perca flavescens]) and cold-water planktivores (e.g., lake trout [Salvelinus namaycush], lake herring [Coregonus artedii], rainbow smelt [Osmerus mordax], and lake whitefish [Coregonus clupeaformis]; Ontario Ministry of Natural Resources unpubl.).
Lakes were sampled every 2 weeks from mid-May until September. At the deep station in each lake, temperature and dissolved oxygen were measured, and samples were taken for crustacean zooplankton, rotifers, and phytoplankton. Crustacean zooplankton were sampled from $5 \mathrm{~m}$ off the lake bottom to the surface using a 110- $\mu \mathrm{m}$ mesh net, $0.5 \mathrm{~m}$ in diameter, which was pulled vertically through the water column. Zooplankton in samples were anesthetized and preserved in 5.5\% sugared and buffered formalin. Separate samples were taken in July and August for rotifers and phytoplankton from the epilimnion using a $2-\mathrm{cm}-$ diameter, 9-m-long vertical tube sampler. The median JulyAugust epilimnetic depth was $5.3 \mathrm{~m}$, ranging from a minimum of $3.4 \mathrm{~m}$ to a maximum of $7.8 \mathrm{~m}$. Although phytoplankton can also be abundant in deeper depth strata, we chose to sample in the epilimnion because our main goal was to observe effects of Bythotrephes, which is most abundant in the epilimnion in lakes in this region (Young and Yan 2008). Rotifers were anesthetized, and both rotifers and phytoplankton were preserved with Lugol's solution. Samples for rotifers and phytoplankton were also taken at one additional station located $500 \mathrm{~m}$ from the deep station, and the two samples were pooled for enumeration. Bythotrephes was sampled at the deep station and four additional stations $(<1 \mathrm{~km})$ from June to September using a $400-\mu \mathrm{m}$ mesh net, $0.5 \mathrm{~m}$ in diameter, which was towed vertically from $5 \mathrm{~m}$ off the lake bottom to the surface.

Composite zooplankton and phytoplankton samples were obtained by pooling equal proportions of each of the nine biweekly zooplankton samples (May to September) and the five biweekly phytoplankton samples (July and August). Composite samples may lead to imprecise estimates of species abundance by over- or under-representing certain taxa; however, a concurrent study in a subset of our study lakes found that crustacean zooplankton taxa were present, on average, on $>50 \%$ of sampling dates (A. Strecker unpubl.). Additionally, our counting protocol was designed to target rare species; thus, this likely represents a small source of variability in our results. Rotifer samples were enumerated from the same five biweekly summer sampling dates and averaged. Crustacean zooplankton were generally identified to species, and juvenile copepods and macroinvertebrates were excluded. Zooplankton species were grouped into size classes $(0-0.4$, $0.4-0.8,0.8-1.2,1.2-1.6$, and $>1.6 \mathrm{~mm}$ ) derived from a concurrent study in a subset of our study lakes (Strecker and Arnott 2008), and they were assigned to functional groups using the classification of Barnett et al. (2007) (Table 2). Rotifers were identified to genus, and phytoplankton were identified to species but grouped at the family level for analyses (i.e., bacillariophyceae, chlorophyceae, chrysophyceae, cryptophyceae, pyrrhophyceae, cyanophyceae). Phytoplankton were also classified into size classes $(<10,10-20,20-35,>35 \mu \mathrm{m})$ and functional groups (motile unicellular, motile colonial, nonmotile colonial, nonmotile unicellular, filamentous, and weakly filamentous). Phytoplankton biovolumes were estimated from geometric shapes (Paterson et al. 2008). Rotifer data were only available for 14 lakes (10 invaded and 4 
Table 3. Principal components analyses of (a) chemical variables and (b) morphological and physical variables, as well as principal coordinates analysis of (c) pelagic planktivore fish community composition for the full 22 lake set and the 14 lake subset used for the rotifer taxonomic composition analyses. Note that yellow perch (Perca flavescens) was present in all lakes and, therefore, had no utility in the analysis. Values are scores along axes I and II.

\begin{tabular}{|c|c|c|c|c|}
\hline & \multicolumn{2}{|c|}{22 lakes } & \multicolumn{2}{|c|}{14 lake subset } \\
\hline $\begin{array}{l}\text { (a) Chemical PCA } \\
\text { Log alkalinity } \\
\mathrm{Ca} \\
\text { Dissolved organic carbon } \\
\text { Conductivity } \\
\mathrm{Mg} \\
\mathrm{NH}_{4} \\
\mathrm{NO}_{3} \\
\text { Total Kjeldahl nitrogen } \\
\mathrm{pH} \\
\text { Total phosphorus } \\
\mathrm{K} \\
\mathrm{Si} \\
\mathrm{Na} \\
\text { Variation explained }\end{array}$ & $\begin{array}{r}0.962 \\
0.903 \\
-0.070 \\
0.976 \\
0.916 \\
0.474 \\
-0.428 \\
0.215 \\
0.902 \\
-0.007 \\
0.915 \\
-0.402 \\
0.577 \\
47 \%\end{array}$ & $\begin{array}{r}-0.182 \\
-0.211 \\
0.763 \\
0.079 \\
-0.235 \\
0.647 \\
-0.039 \\
0.937 \\
-0.307 \\
0.698 \\
0.264 \\
0.492 \\
0.471 \\
24 \%\end{array}$ & $\begin{array}{r}0.972 \\
0.848 \\
-0.190 \\
0.987 \\
0.920 \\
0.744 \\
-0.354 \\
0.512 \\
0.875 \\
0.020 \\
0.933 \\
-0.537 \\
0.803 \\
54 \%\end{array}$ & $\begin{array}{r}0.052 \\
0.082 \\
-0.859 \\
0.102 \\
0.015 \\
-0.198 \\
0.679 \\
-0.721 \\
0.339 \\
-0.839 \\
-0.134 \\
-0.251 \\
0.085 \\
21 \%\end{array}$ \\
\hline $\begin{array}{l}\text { (c) Fish PCoA } \\
\text { Lake herring (Coregonus artedi) } \\
\text { Lake whitefish (Coregonus clupeaformis) } \\
\text { Rainbow smelt (Osmerus mordax) } \\
\text { Variation explained }\end{array}$ & $\begin{array}{c}0.882 \\
0.801 \\
-0.156 \\
41 \%\end{array}$ & $\begin{array}{r}0.074 \\
-0.293 \\
-0.957 \\
30 \%\end{array}$ & $\begin{array}{c}-0.834 \\
-0.738 \\
0.679 \\
51 \%\end{array}$ & $\begin{array}{l}0.212 \\
0.440 \\
0.704 \\
20 \%\end{array}$ \\
\hline
\end{tabular}

reference: Table 1). For additional details on sampling and enumeration, see Hovius et al. (2006) and Strecker et al. (2006).

Depth-integrated epilimnetic samples for chemical analyses (alkalinity, calcium, dissolved organic carbon, conductivity, magnesium, $\mathrm{NH}_{4}, \mathrm{NO}_{3}$, total Kjeldahl nitrogen, $\mathrm{pH}$, total phosphorus [TP], potassium, silica, and sodium) were taken in mid-July 2003 at the deep station of each lake. Following Ontario Ministry of the Environment (2003) protocols, samples were filtered through an $80-\mu \mathrm{m}$ mesh in the field to remove zooplankton in order to decrease variability of TP due to sporadic inclusion of zooplankton in water samples of these low-productivity lakes.

Statistical analyses-Multivariate ordination techniques were used to test the relative contributions of Bythotrephes and other environmental variables in explaining variation in crustacean zooplankton, rotifer, and phytoplankton communities. Redundancy analysis (RDA) was performed using Canoco 4.5 (ter Braak and Šmilauer 2002), because preliminary analyses using detrended correspondence analysis suggested that linear ordination techniques were appropriate. Species data were Hellinger-transformed prior to analysis because the Euclidean distance measure used in RDA is inappropriate for raw data containing many null values (Legendre and Gallagher 2001). Because there were large numbers of predictor variables in comparison to the number of sites, many of which were also highly correlated, we reduced the variables into independent linear combinations of variables using principal components analysis (PCA) (see Graham [2003] for use in multiple regression). For example, we constructed a PCA from variables that describe the morphological and physical characteristics of lakes, such as elevation, maximum depth, Secchi depth, and surface area (hereafter morphological PCA). Additionally, a PCA was performed on chemical variables (chemical PCA), and a principal coordinates analysis (PCoA) was performed on pelagic planktivore fish community composition (presence or absence: fish PCoA). The scores of each lake on axis I and axis II were then used in redundancy analyses, since these axes represented a large part of the variability in physical, morphological, chemical, and planktivorous fish community characteristics: Morphological PCA axes I and II captured $49 \%$ and $28 \%$ of variation, respectively, chemical PCA axes I and II explained $47 \%$ and $24 \%$ of variation, respectively, and fish PCoA axes I and II explained $41 \%$ and $30 \%$ of variation, respectively (Table 3). Separate PCAs and PCoAs were also performed on the subset of lakes used for the analysis of rotifer taxonomic composition (14 lakes); these analyses yielded similar results to the full 22 lake data set (Table 3). Bythotrephes was entered as a binary variable (presence or absence), and an additional variable of time since invasion 
was tested (Table 1). Variables were considered significant at $p<0.05$.

Variation partitioning was used to separate significant variation explained by Bythotrephes, environmental variables, and any covariation between the invader and the environment (Peres-Neto et al. 2006). The method used controls for the inflated variance that occurs with increased numbers of variables in ordinations and, therefore, will enact a greater penalty on the environmental data set, which contains more variables compared to the Bythotrephes data set, which contains two variables (presence or absence, time since invasion). Variation partitioning and significance testing of environmental and Bythotrephes variables (5000 permutations) were conducted in the $R$ library vegan ( $\mathrm{R}$ Development Core Team 2010). Note that significance testing cannot be performed on the covariation term between Bythotrephes and the environment.

Finally, we used structural equation modeling (SEM) to elucidate the nature of the interactions between variables. SEM is a technique that allows variables to simultaneously be predictors and responses, and, therefore, it can be useful in testing theories about causal relationships in complex networks (Grace 2006). A theoretical model is specified a priori, and thus, if the observed data are a good fit to the model, there is support for the relationships identified in the theoretical model. For example, SEM has been successfully used to confirm the direct and indirect pathways that were hypothesized to operate in kelpinvertebrate coastal ecosystems (Arkema et al. 2009). Our small sample size $(n=22)$ precluded the usage of SEM as a confirmatory technique; rather, it must be seen as an exploratory assessment of our observational data (Kline 2005). Because we were interested in specific interactions, e.g., the direct and indirect influence of water chemistry and Bythotrephes on zooplankton and phytoplankton, we ran two separate models testing the variables that are known to influence both zooplankton and phytoplankton (chemistry axis I and morphological axis I), as well as Bythotrephes. We used the $\mathrm{R}$ library sem (structural equation models: Fox 2006) to estimate standardized path coefficients, test model fit, and generate $R^{2}$ values for the amount of variation explained by our models. Models were fit by maximum likelihood, and Bayesian information criteria (BIC) scores were generated, where lower scores indicate more parsimonious models. The strength of indirect interactions was estimated by multiplying the standardized path coefficients (e.g., the indirect effect of morphological axis I on phytoplankton $=$ direct effect of morphological axis I on zooplankton $\times$ direct effect of zooplankton on phytoplankton) (Grace 2006). An important distinction in SEM is that a model is considered a good fit when there are no significant differences $(p>0.05)$ between expected and observed covariances, as assessed with a $\chi^{2}$ test (Grace 2006).

\section{Results}

Bythotrephes variables were important predictors of crustacean zooplankton community size structure, explaining $23 \%$ of variation $(p=0.01)$, but they were not significant for other zooplankton metrics, explaining only $5 \%$ of variation in taxonomic structure $(p=0.09)$ and $8 \%$ of variation in functional groups $(p=0.14)$ (Fig. 1). Bythotrephes variables also explained a significant amount of variation in rotifer community taxonomic composition (61\% of variation: $p=0.04$ ) (Fig. 1). Environmental variables explained significant variation in crustacean zooplankton size structure (34\% of variation: $p<0.01$ ) and taxonomic structure (18\% of variation: $p<0.01$ ) (Fig. 1). Environmental variables did not explain significant variation in zooplankton functional groups $(8 \%$ of variation: $p=0.24$ ) (Fig. 1) or rotifer community composition (9\%: $p=0.36$ ) (Fig. 1). Covariation between the invader and environmental variables also failed to explain any variability in crustacean zooplankton or rotifer communities (Fig. 1). The compositional effects of environmental variables and Bythotrephes on crustacean zooplankton and rotifer communities have been welldescribed elsewhere (Hovius et al. 2006; Strecker et al. 2006); please see Fig. 2 for specific relationships between variables and communities. It is worth noting that Bythotrephes presence is significant in some ordination biplots, but Bythotrephes variables are not significant in the variation partitioning analysis (see Figs. 1,2): this likely reflects the weak effect of the additional variable, time since invasion.

Bythotrephes variables explained significant independent variation in phytoplankton taxonomic groups (13\% of variation purely explained: $p=0.03$ ) but did not have a significant influence on variation in functional groups (3\% of variation: $p=0.24$ ) (Fig. 1). Additionally, Bythotrephes did not explain variation in phytoplankton size structure (2\% of variation: $p=0.34$ ): There was no difference in edible phytoplankton $(<35 \mu \mathrm{m})$ biovolume in invaded lakes compared to noninvaded lakes (invaded: $1280 \mathrm{~mm}^{3} \mathrm{~mL}^{-1} \pm 99$; noninvaded: $1214 \pm 98 \mathrm{~mm}^{3} \mathrm{~mL}^{-1}$, $t$-test, $t=-1.47$, df $=20, p=0.16$ ). Because it is possible that changes in phytoplankton in invaded systems may be more pronounced in lakes at higher trophic status (i.e., oligotrophic-mesotrophic), we assessed the deviation of edible phytoplankton biovolume in invaded lakes from the average biovolume in noninvaded lakes along a gradient of trophic status, as measured by total phosphorus. Trophic status had no effect on invaded lake edible phytoplankton biovolume $\left(R^{2}=0.05, p=0.41\right)$. Environmental variables accounted for minor and insignificant variation in phytoplankton size structure (11\% of variation: $p=0.17$ ) and functional groups (10\% of variation: $p=0.12$ ) (Fig. 1). However, environmental variables explained a significant portion of variation in phytoplankton taxonomic structure (23\% variation: $p=0.02$ ) (Fig. 1). Covariation between Bythotrephes and environmental variables accounted for some variation in phytoplankton community size structure (12\%), functional groups (7\%), and taxonomic structure (3\%) (note that significance of this fraction cannot be tested; Fig. 1). See Fig. 3 for specific relationships between variables and phytoplankton communities.

Because past studies have not documented significant independent effects of Bythotrephes on phytoplankton taxonomic structure, we expand on this result here. 


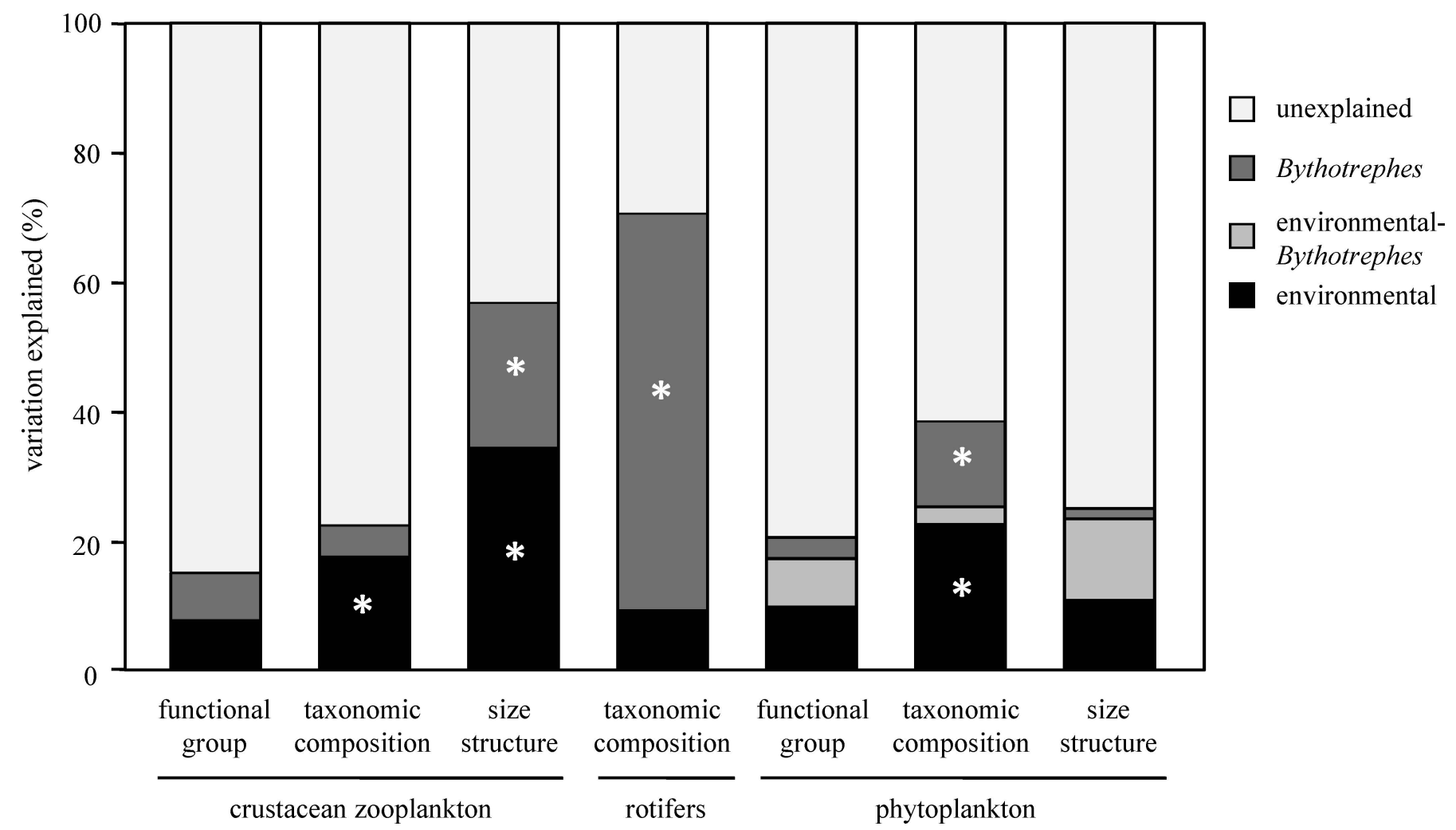

Fig. 1. Relative importance of Bythotrephes variables, environment-Bythotrephes covariation, and environment in explaining variation in crustacean zooplankton functional groups, taxonomic composition, and size structure, rotifer taxonomic composition, and phytoplankton functional groups, taxonomic composition, and size structure. Significance of fractions is indicated by: $* p<0.05$. Note that significance testing of the environment-Bythotrephes fraction could not be performed.

Chlorophytes and cyanophytes were positively correlated with: (1) chemical PCA axis I (representing conductivity and ionic strength; Table 3), (2) morphological PCA axis I (representing lake size and depth; Table 3), and (3) Bythotrephes presence (Fig. 3b). Chrysophytes were opposite in direction to chlorophytes and cyanophytes (Fig. 3b). Cyanophytes and pyrrhophytes were positively related to Bythotrephes, while bacillariophytes were uncorrelated with the presence of the invader (Fig. 3b). Additionally, we tested for differences in the log-transformed biovolumes of specific phytoplankton taxonomic groups that our ordinations identified as correlated with Bythotrephes: Pyrrhophyte biovolume was significantly greater in invaded compared to noninvaded lakes ( $t$-test, $t=-2.26$, df $=$ $20, p=0.03)$, whereas chrysophyte biovolume was significantly smaller in invaded lakes compared to noninvaded lakes ( $t$-test, $t=4.10, \mathrm{df}=20, p<0.01)$. Cyanophyte biovolume was slightly greater in invaded lakes than in noninvaded lakes, but not significantly so ( $t$ test, $t=-1.84$, df $=20, p=0.08$ ). Although slight differences in sampling protocols may have led to a greater representation by metalimnetic colonial chrysophytes in Blue Chalk and Red Chalk lakes, chrysophytes were $3 \times$ more abundant in the remainder of noninvaded lakes compared to invaded lakes ( $t$-test, $t=3.35, \mathrm{df}=20, p<$ 0.01 ), suggesting that the high correlation with RDA axis I is not an artifact.
Because previous research has found little evidence of omnivory by Bythotrephes (Schulz and Yurista 1995), we infer that effects of the invader on algal communities are operating indirectly through the zooplankton community. We explored the importance of zooplankton in shaping the covariation effect between Bythotrephes and environmental variables on phytoplankton size structure by directly incorporating zooplankton community size structure into ordination analyses. Here, we partitioned variation between three compartments: environment, Bythotrephes, and zooplankton. Like the two-compartment variation partitioning, this analysis allows us to control for covariation among variables and assess independent and shared contributions from sets of variables. We chose to use zooplankton size structure because this grouping was most influenced by environmental variables and Bythotrephes (Fig. 1). If the effect of Bythotrephes on phytoplankton is truly indirect and mediated through zooplankton, then we should predictably see a large reduction in independent variation explained by the invader. In contrast to the twocompartment test, Bythotrephes and environmental variables explained no independent variation in the threecompartment test, and only a moderate fraction of shared variation in phytoplankton size (10\%; Fig. 4). However, shared variation between environment and zooplankton explained $26 \%$ of variation in phytoplankton size structure, and shared variation between zooplankton and Bytho- 

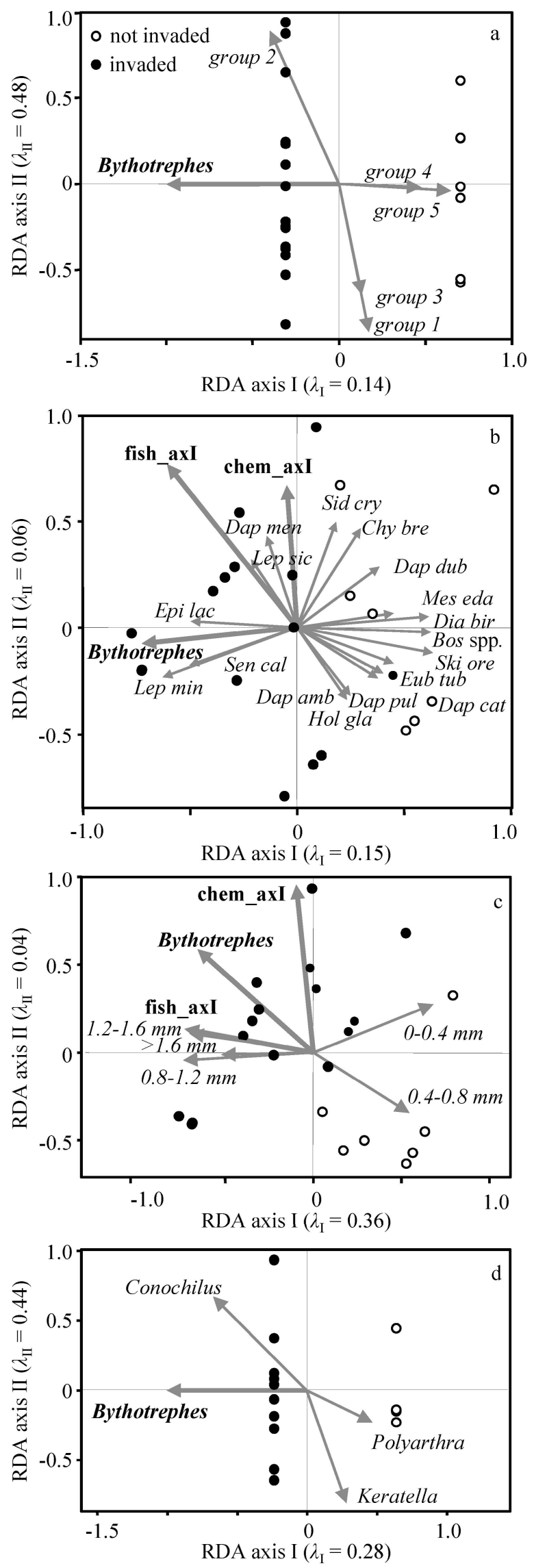

trephes and among all three sets of variables accounted for an additional $11 \%$ and $2 \%$ of algal community size structure, respectively (Fig. 4). This suggests that the effect of Bythotrephes on phytoplankton communities may be mediated via the invader's effect on the zooplankton community along gradients of environmental conditions.

To further explore possible mechanisms that may be driving the effects of Bythotrephes, zooplankton, and environmental factors on phytoplankton community structure, we used the site scores from chemical PCA axis I and morphological PCA axis I as examples of indirect interactions. Chemical axis I was positively correlated with various ions, including $\mathrm{Ca}$ and $\mathrm{K}$, as well as $\mathrm{pH}$ and alkalinity, whereas morphological axis I was correlated with area and depth (Table 3). Both axes were significant in phytoplankton ordinations (Fig. 3). Calcium (Pinel-Alloul et al. 1995; Jeziorski et al. 2008), other ions (Pinel-Alloul et al. 1990), pH (Sprules 1975), and lake size (Keller and Conlon 1994) are known to influence crustacean zooplankton community structure. We used linear regression to compare the responses of phytoplankton in invaded and reference lakes to chemical and morphological axis I. Given that we saw the greatest covariation effect for phytoplankton size structure, we explored this further using the biovolume most likely to be affected by herbivorous cladocerans and copepods, edible phytoplankton $(<$ $35 \mu \mathrm{m})$.

Edible phytoplankton biovolume was not significantly influenced by chemical axis I (invaded: $R^{2}=0.13, p=0.19$; not invaded: $R^{2}=0.06, p=0.64$; Fig. 5 a) or morphological axis I (invaded: $R^{2}=0.03, p=0.49$; not invaded: $R^{2}=$ $0.27, p=0.29$; Fig. 5c). Additionally, the biomass of the major herbivore group responsive to Bythotrephes invasion (cladoceran zooplankton) did not change significantly along chemistry axis I in invaded lakes $\left(R^{2}=0.23, p=\right.$ 0.07 ) or noninvaded lakes $\left(R^{2}=0.02, p=0.78\right)$ (Fig. 5b). However, cladoceran biomass declined significantly along morphological axis I in invaded lakes $\left(R^{2}=0.43, p<0.01\right)$ but was unaffected by lake morphology in noninvaded

Fig. 2. Redundancy analysis (RDA) of crustacean zooplankton (a) functional groups, (b) taxonomic composition, (c) size structure, and (d) rotifer taxonomic composition. Site scores of invaded and noninvaded lakes are indicated with a closed and open circle, respectively. Species scores are indicated by the thin arrows and italicized font. Significant variables are represented by thick arrows and bold font. Functional classification of crustacean zooplankton follows Barnett et al. (2007); see Table 2 for description. Abbreviations: chem_axI, chemical PCA axis I; fish_axI, fish PCoA axis I; Bos spp., Bosmina spp.; Chy bre, Chydorus brevilabris; Dap amb, Daphnia ambigua; Dap cat, Daphnia catawba; Dap dub, Daphnia dubia; Dap men, Daphnia mendotae; Dap pul, Daphnia pulex; Dia bir, Diaphanosoma birgei; Epi lac, Epischura lacustris; Eub tub, Eubosmina tubicen; Hol gla, Holopedium glacialis; Lep min, Leptodiaptomus minutus; Lep sic, Leptodiaptomus sicilis; Mes eda, Mesocyclops edax; Sen cal, Senecella calanoides; Ski ore, Skistodiaptomus oregonensis; Sid cry, Sida crystallina. Note that rare species (occurrence in $<4$ lakes) were removed prior to ordination analyses and that species located close to the origin have also been removed. 

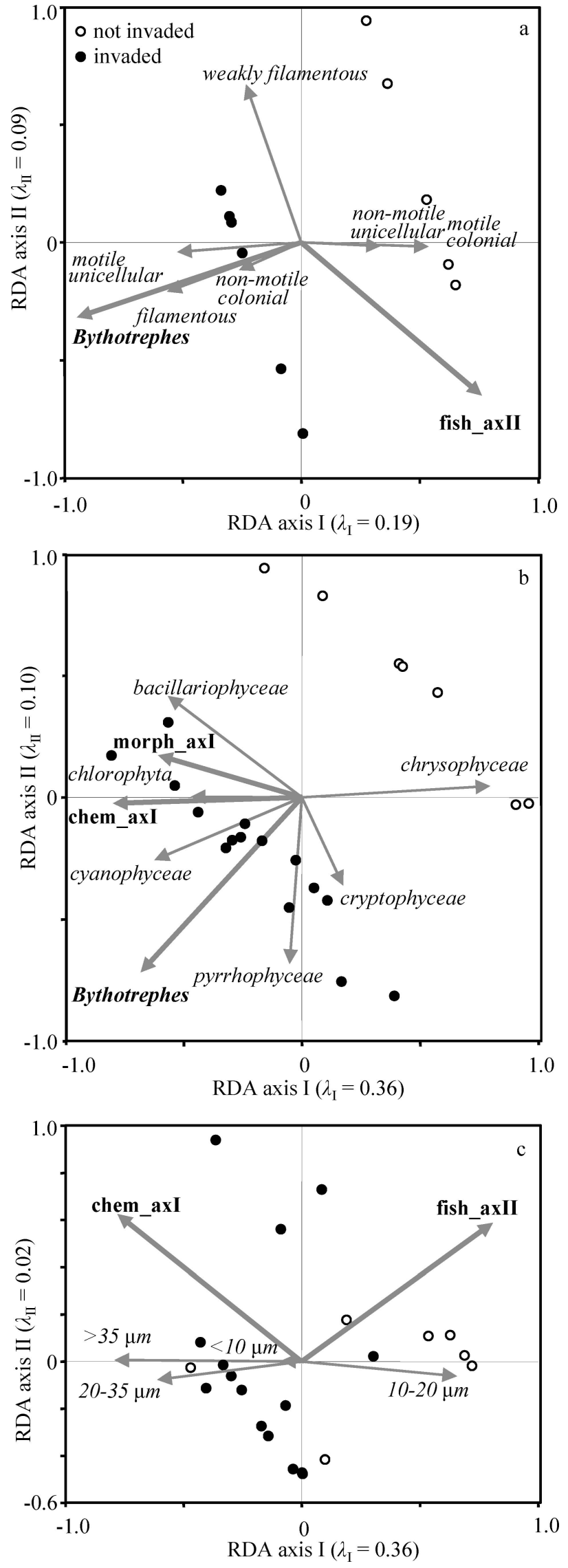

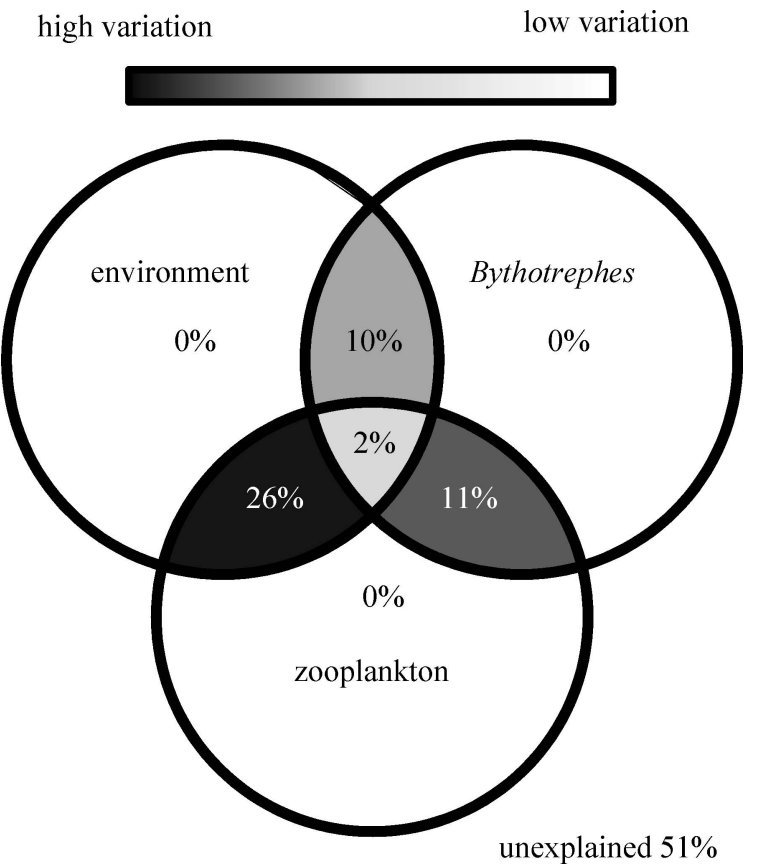

Fig. 4. Variation partitioning of phytoplankton size structure into independent and shared variation $(\%)$ from three sets of variables: environment, Bythotrephes, and zooplankton size structure. Note that significance testing of the joint influence of variables could not be performed. Darker colors indicate greater variation explained.

lakes $\left(R^{2}=0.17, p=0.36\right)$ (Fig. 5d). The lack of directional change along environmental gradients in both cladoceran zooplankton and edible phytoplankton in noninvaded lakes suggests that cladoceran zooplankton grazers were either in balance with their food resources or not controlling edible phytoplankton in noninvaded lakes. The lower biomass of cladocerans and their decrease along morphological axis I without a corresponding increase in phytoplankton response in invaded lakes support the latter hypothesis: We explored this further by examining the relationship between cladoceran biomass and edible phytoplankton biovolume (Fig. 6). We observed no significant relationship between cladoceran biomass and edible phytoplankton biovolume in either instance, further supporting the latter hypothesis (noninvaded lakes: $R^{2}=0.47, p=$ 0.13 ; invaded lakes: $R^{2}=0.02, p=0.64$; Fig. 6).

Finally, we assessed the strength of the direct and indirect interactions among water chemistry and morphological variables, Bythotrephes, cladoceran biomass, and edible phytoplankton biovolume using structural equation models (SEM) (Fig. 7). The model with morphological axis I was an adequate fit to our observed data (i.e., no significant differences between the expected and observed

$\leftarrow$

Fig. 3. Redundancy analysis (RDA) of phytoplankton (a) functional groups, (b) taxonomic composition, and (c) size structure. Symbols and abbreviations are as in Fig. 2. Abbreviations: fish_axII, fish PCoA axis II; morph_axI, morphological PCA axis I. 

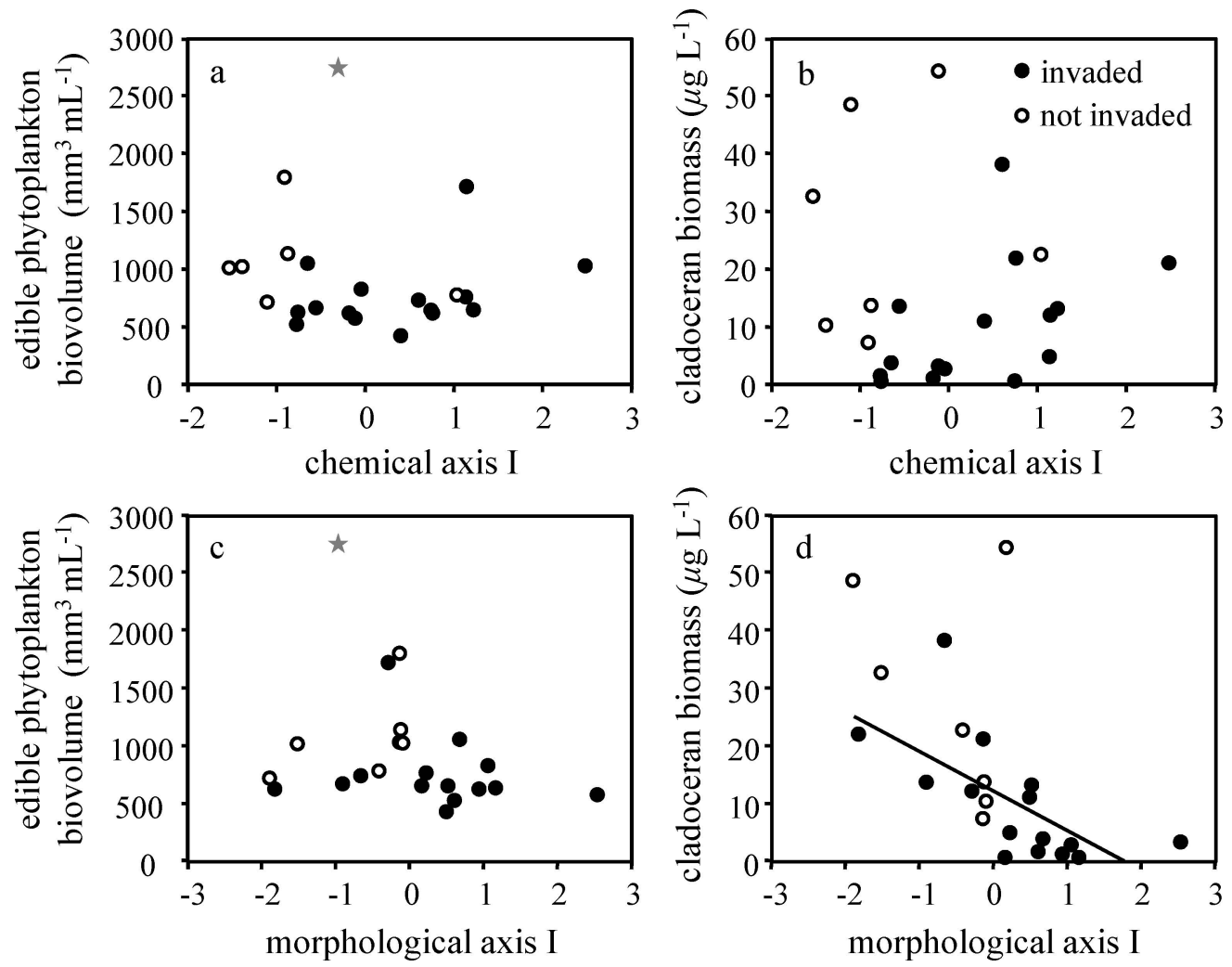

Fig. 5. The relationship between (a, b) chemical and (c, d) morphological PCA axis I and edible phytoplankton biovolume $(<35 \mu$ m; $\mathrm{mm}^{3} \mathrm{~mL}^{-1}$ ) and cladoceran biomass $\left(\mu \mathrm{g} \mathrm{L}^{-1}\right)$ in noninvaded (open circles) and invaded (closed circles) lakes. Significant regression lines for the invaded lakes are indicated by a solid line. Edible phytoplankton from Doe Lake (indicated by a star) was excluded, as it was an outlier. Doe Lake is a large shallow lake with a small deep hole region, which is consistent with a highly mixed water column sustaining high biomasses and nutrient loading from sediments, unlike the remainder of the lakes.

model; model $\left.\chi^{2}=5.34, p=0.07\right)$, whereas the model that included chemistry axis I was not a good fit (model $\chi^{2}=$ 9.94, $p=0.01$ ) (Fig. 7); therefore, we will not consider the chemistry model further. In agreement with our other analyses, morphological axis I had moderate and nonsignificant direct effects on edible phytoplankton, as did cladoceran zooplankton (Fig. 7). However, morphological axis I had significant direct effects on cladocerans, which, when combined with the effects of cladocerans on edible phytoplankton, had substantial indirect effects on edible phytoplankton $(-0.60 \times-0.42=0.25$; Fig. 7). In contrast, Bythotrephes had an indirect positive effect on edible phytoplankton biovolume that was weaker than the effects of morphological axis I $(-0.30 \times-0.42=0.13$; Fig. 7).

\section{Discussion}

We observed patterns in the lower food web that are consistent with both indirect and direct effects of Bythotrephes on planktonic communities in freshwater lakes. Two main types of effects could be distinguished. First, there were top-down effects on crustacean zooplankton and rotifers related to Bythotrephes presence. We found significant effects of Bythotrephes on zooplankton community size structure, but not composition. This is in contrast to other studies that have documented strong effects of Bythotrephes on zooplankton community biodiversity and the loss of some cladoceran species (Boudreau and Yan 2003; Barbiero and Tuchman 2004; Hovius et al. 2007). Changes in the composition of the zooplankton community suggest that the invasion of Bythotrephes may have significant consequences for size-related aspects of the zooplankton community functioning, such as grazing and metabolism. It is important to note that the top-down effects that have been observed between Bythotrephes and crustacean zooplankton include both direct consumptive and indirect nonlethal effects (Pangle et al. 2007), which will accentuate the effects on zooplankton community metabolism.

The second main type of effect that we were able to detect with our comparative survey was indirect effects of invasion on phytoplankton communities. We found evidence for significant responses in phytoplankton taxonomic composition in the epilimnion of Bythotrephes-invaded lakes but no change in phytoplankton biomass (Figs. 1, 3). This concurs with our hypothesis that traditional trophic cascades resulting in changes in biomass would be absent from these oligotrophic lakes, but that more subtle shifts in phytoplankton community composition may result from an invasion. To determine the nature of the influence of Bythotrephes on phytoplankton, it was necessary to 


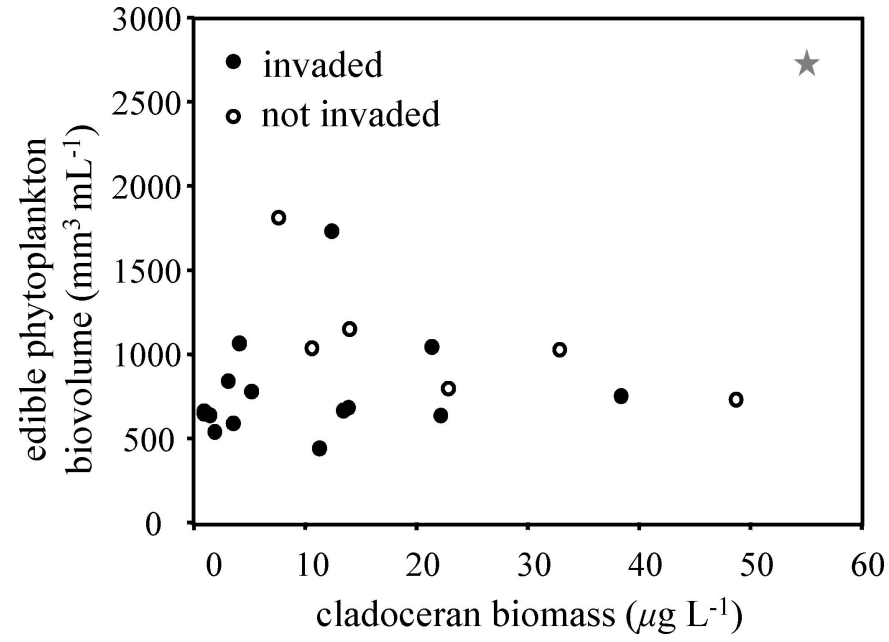

Fig. 6. The relationship between cladoceran biomass $\left(\mu \mathrm{g} \mathrm{L} \mathrm{L}^{-1}\right)$ and edible phytoplankton biovolume $(<35 \mu \mathrm{m}$; $\mathrm{mm}^{3} \mathrm{~mL}^{-1}$ ) in noninvaded (open circles) and invaded (closed circles) lakes. Correlations between variables were not significant $(p>0.05)$. The star indicates a noninvaded lake (Doe Lake) that was excluded from this analysis because it was an obvious outlier with both high cladoceran abundance and high phytoplankton biovolume. The highly mixed water column and influence of nutrient loading from the sediments potentially preclude topdown control of phytoplankton.

incorporate both environmental variation and zooplankton size structure into our models. Joint control of lower trophic levels from both top-down and bottom-up factors has been demonstrated previously (Leibold et al. 1997 and references therein), and it is not unreasonable to expect that environmental variables can affect both phytoplankton and zooplankton, generating indirect trophic interactions. We demonstrated these interactions with structural equation models (SEMs) on environmental variables that are representative of gradients across lakes (chemical and morphological axis I). Many environmental variables, including calcium and lake size, can have significant influences on crustacean zooplankton community structure (Keller and Conlon 1994; Jeziorski et al. 2008). We found that the chemical model was a poor fit to the data, but that the morphological model was a good fit, indicating that indirect trophic interactions are important structuring forces in these systems. These indirect trophic interactions are mediated by Bythotrephes: Morphological scores had a lesser effect on cladocerans in invaded lakes compared to noninvaded lakes (significant invasion effect: morphological analysis of covariance [ANCOVA] $F_{1,18}=9.46, p<$ $0.01)$. Thus, what appears to be an effect of the environment (e.g., lake size gradient) on edible phytoplankton in invaded lakes is instead partially a result of a decoupling of the predator-prey interaction between the most competitive herbivores (cladocerans) and their phytoplankton prey. This decoupling likely results from reduced abundance of cladocerans, particularly the important grazers such as Daphnia spp. Strayer et al. (2008) found similar complex indirect interactions between environmental drivers and the grazing effects of another

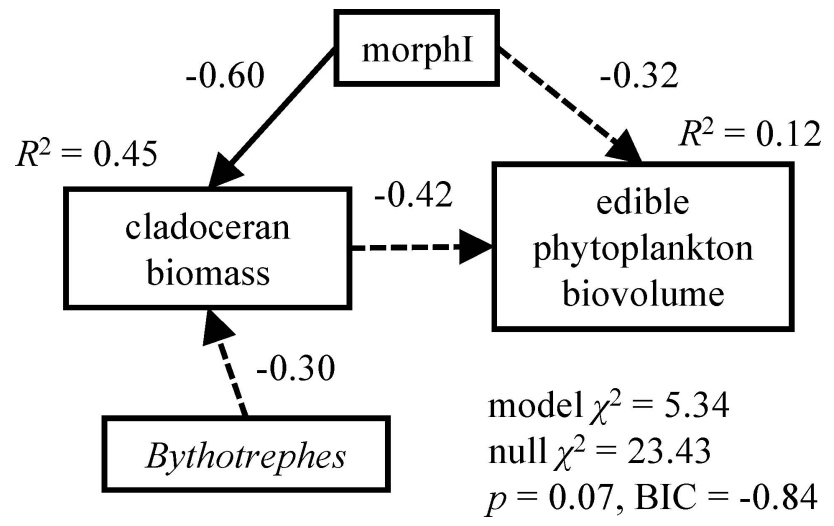

Fig. 7. Results of structural equation modeling. Separate models were performed to test the direct and indirect effects of morphological axis I, as well as Bythotrephes, on cladoceran biomass and edible phytoplankton biovolume. Arrows drawn between boxes and their associated numerical values represent standardized path coefficients, and significant pathways are indicated by solid arrows, whereas nonsignificant pathways are represented by dashed arrows. Overall model fit was assessed by $\chi^{2}$, where $p>0.05$ is considered a good model fit. Error terms were included for each of the variables in the model but have been excluded here for simplicity. Variation explained $\left(R^{2}\right)$ is reported for cladoceran biomass and phytoplankton biovolume.

invader (the zebra mussel, Dreissena polymorpha) in the Hudson River. These types of complex relationships between the environment and invasive species may render the prediction of effects and the management of invaders more context-dependent than previously acknowledged, necessitating the inclusion of environmental gradients in studies of invasions. In particular, this should be the case for mid-trophic-level invaders, for which many links with other members of the food web are possible.

Top-down effects of Bythotrephes (independent of environment) were attenuated somewhat at the primaryproducer trophic level. Other studies in this region have detected declines in zooplankton biomass (Boudreau and Yan 2003) in addition to the changes we document here. Such changes to zooplankton community structure and biomass would lead us to expect concomitant changes in the phytoplankton community (biovolume and composition) (Cyr 1998). While we observed changes in phytoplankton composition attributable to Bythotrephes, we did not observe the expected significant increases in lakewide phytoplankton biovolume. Results from previous studies are equivocal on this matter. Lack of increases in phytoplankton biomass at the whole-lake scale was also observed by Lehman (1988) in Lake Michigan and by Strecker and Arnott (2008) in a subset of our lakes. In experimental mesocosms, increases in chlorophyll (phytoplankton biomass) in the presence of Bythotrephes, consistent with trophic cascades, were observed (Strecker and Arnott 2005). Conversely, Wahlström and Westman (1999) observed no significant effect of Bythotrephes on chlorophyll in enclosures. Thus, it is still uncertain as to whether Bythotrephes leads to increases in phytoplankton that are characteristic of traditional trophic cascades, especially with aggregate measures of the phytoplankton 
community (i.e., biovolume). Such trophic effects may be precluded in our region at the whole-lake scale because the low nutrient status of the lakes may be the more dominant structuring feature for phytoplankton, as $\mathrm{McQu}-$ een et al. (1986) has suggested should be the case for oligotrophic systems. Additionally, trophic cascades can be dampened by compensatory dynamics in food webs (Pace et al. 1999).

Although we failed to see differences in phytoplankton biomass attributable to a trophic cascade in invaded lakes, we did observe shifts in the taxonomic composition of the phytoplankton that have not been previously reported. In invaded lakes, we found that pyrrhophyte and cyanophyte biovolumes were greater relative to noninvaded lakes. We hypothesize that increases in pyrrhophytes and cyanophytes are related to reduced grazing pressure from a less abundant cladoceran community in invaded lakes. Pyrrhophytes are generally larger, highly motile cells, which may be more difficult for smaller zooplankton to handle and consume. The greater biovolume of cyanophytes in invaded lakes was the result of increases in less edible filamentous taxa ( $t$-test, $t=2.51, \mathrm{df}=20, p=0.02$; Fig. 3a). The shift in the zooplankton of invaded lakes to a more copepod-dominated community may be responsible for the increases in filamentous taxa, because copepods are generally less effective grazers.

The other important shift with Bythotrephes invasion was a loss of chrysophyte biovolume. Losses occurred as a result of both motile colonial and nonmotile unicellular functional groups in invaded lakes (B. Beisner unpubl.). This is a counterintuitive result; we would have expected, as was the case for pyrrhophytes and cyanophytes, to see chrysophytes increase in Bythotrephes lakes as a result of reduced grazing pressure from crustacean zooplankton. These results also appear to conflict with a recent study of long-term changes in phytoplankton biovolume in Harp Lake, an invaded lake included in our study. Over a 25 -yr period, Paterson et al. (2008) noted significant increases in chrysophyte biovolume, speculating that the recent invasion by Bythotrephes may have contributed to alterations in food webs that indirectly altered phytoplankton composition and biovolume. Large, colonial chrysophytes are less favorable to size-selective herbivores such as the rotifer Conochilus, which peaked in Harp Lake following invasion (Hovius et al. 2007). In part, the apparent discrepancy between the spatial and temporal studies may be explained by differences in study design. A more detailed examination of seasonal phytoplankton biovolume in Harp Lake in 2005 showed that only a quarter of the total ice-free phytoplankton biovolume $(\sim 27 \%)$ occurs during July and August, the months of focus in our study (A. Paterson unpubl.). When the entire ice-free season is considered, chrysophyte and diatom species dominate the phytoplankton assemblage, but these groups are generally less important during the summer months. Thus, the assemblage-wide changes reported by Paterson et al. (2008) following invasion may not have been detectable with our shortened sampling season. Furthermore, the loss of chrysophytes from the epilimnion in our spatial survey may have been balanced by an increase in the abundance of metalimnetic colonial chrysophytes in the lakes. However, our study examined epilimnetic phytoplankton communities only, and so we cannot confirm or refute this hypothesis.

In some instances, our ability to attribute variability in communities to measured factors was low. This likely reflects a combination of measurement and process error. As mentioned already, our sampling protocol focused on the epilimnion of lakes, potentially missing changes in metalimnetic algal biovolume, which dominates in midsummer. However, the effects of Bythotrephes on zooplankton have been primarily observed in the epilimnion (Strecker and Arnott 2008), and thus we would expect to see the greatest effects on phytoplankton in the epilimnion as well. Additionally, we combined samples from several sampling dates into single composite samples, which may have reduced our ability to detect subtle temporal dynamics. For example, we observed low explanatory power of cladoceran biomass on edible phytoplankton biovolume in all of our study lakes. However, other surveys (Pérez-Fuentetaja et al. 2000) and experiments (Strecker and Arnott 2008) in the region with better temporal resolution (i.e., comparison of samples taken at the same time period) have also observed weak relationships between zooplankton and phytoplankton, suggesting that this is a more widespread phenomenon and is not related to our study protocols. Finally, variation explained by Bythotrephes was generally small: This may be the result of several factors, including the inherent temporal variability in abundance of the invader (Strecker et al. 2006), as well as the recent invasion of several of our study lakes (first detected the year that we sampled in five lakes). There is evidence that the structure of lake food webs may modify the effects of Bythotrephes (Young and Yan 2008), as well as invader density (Hovius et al. 2006) and time lag (Yan and Pawson 1997) effects. These factors may all preclude a single explanation for large components of variation in communities with the variables used here.

Predatory invasive species may have stronger top-down influences than native predators, especially early in the invasion process. There is evidence that prey naiveté may be particularly prevalent in freshwater systems (Cox and Lima 2006), which may allow for stronger immediate trophic effects and, therefore, greater potential for trophic cascades. Our study was conducted on a landscape of lakes in which invasion by Bythotrephes is still actively under way, and many of our invaded lakes represent relatively recent invasions, and therefore have strong potential for top-down effects. Over time, as prey communities are shaped by Bythotrephes predation and as prey develop new predator-evasion strategies, we expect the observable changes to food webs to lessen (Pangle et al. 2007). Despite this, time since invasion was not a significant factor in our analyses, suggesting that prey communities have not yet developed effective responses to invasion.

Although the results of our cross-lake comparison may be somewhat restricted to one region, it is a landscape typical of the lake-dominated Boreal Shield biome. Lakes cover $10 \%$ of the boreal forest globally, occupying roughly $1.3 \times 10^{6} \mathrm{~km}^{2}$ (Molot and Dillon 1996), and $>700,000$ of these lakes are found in eastern temperate Canada (Minns et al. 1990). Bythotrephes continues to spread to a large 
number of lakes (Ontario Federation of Anglers and Hunters 2010) in the susceptible low-productivity boreal ecozone (Vander Zanden et al. 2003), as well as temperate ecozones in northeastern United States (Johnson et al. 2008), suggesting that greater understanding of the complex interactions between invaders and ecosystem processes is necessary.

Our study indicates that invasion can alter the fundamental processes in the pelagic zone of freshwater lakes, altering interactions between zooplankton and phytoplankton trophic levels and between environmental drivers and the phytoplankton community. The complexity of intertrophic and trophic-environmental interactions suggests that simple, general relationships cannot describe or predict invader effects at the ecosystem level. Rather, our ability to predict future change and manage these vital ecosystems will depend on understanding effects within the environmental and invasion history context.

\section{Acknowledgments}

We thank the Dorset Environmental Science Centre for providing logistical support for this study and Jonathon Hovius, Joelle Young, Sophie Foster, Greg Puncher, Emily Parrott, and Lisa Nordin for assistance in the field and long conversations about Bythotrephes. William Taylor, Gary Sprules, and Michael Arts assisted with the study design. We thank two anonymous reviewers for constructive comments. Funding was provided by a Natural Sciences and Engineering Research Council of Canada postgraduate scholarship to A.L.S. and Discovery Grants to S.E.A. and B.E.B., Queen's University, Department of Fisheries and Oceans Canada, and the Ontario Ministry of the Environment.

\section{References}

Arkema, K. K., D. C. Reed, and S. C. Schroeter. 2009. Direct and indirect effects of giant kelp determine benthic community structure and dynamics. Ecology 90: 3126-3137, doi:10.1890/08-1213.1

Barbiero, R. P., and M. L. Tuchman. 2004. Changes in the crustacean communities of Lakes Michigan, Huron, and Erie following the invasion of the predatory cladoceran Bythotrephes longimanus. Can. J. Fish. Aquat. Sci. 61: 2111-2125, doi:10.1139/f04-149

Barnett, A. J., K. Finlay, and B. E. Beisner. 2007. Functional diversity of crustacean zooplankton communities: Towards a trait-based classification. Freshw. Biol. 52: 796-813, doi:10. 1111/j.1365-2427.2007.01733.x

Beisner, B. E., P. R. Peres-Neto, E. S. Lindström, A. Barnett, AND M. L. Longhi. 2006. The role of environmental and spatial processes in structuring lake communities from bacteria to fish. Ecology 87: 2985-2991, doi:10.1890/0012-9658 (2006)87[2985:TROEAS]2.0.CO;2

Boudreau, S. A., And N. D. Yan. 2003. The differing crustacean zooplankton communities of Canadian Shield lakes with and without the nonindigenous zooplanktivore Bythotrephes longimanus. Can. J. Fish. Aquat. Sci. 60: 1307-1313, doi:10.1139/ f03-111

CARPENTER, S. R., AND OTHERS. 1987. Regulation of lake primary productivity by food web structure. Ecology 68: 1863-1876, doi: $10.2307 / 1939878$

Cox, J. G., And S. L. Lima. 2006. Naiveté and an aquaticterrestrial dichotomy in the effects of introduced predators. Trends Ecol. Evol. 21: 674-680, doi:10.1016/ j.tree.2006.07.011
CYr, H. 1998. Cladoceran- and copepod-dominated zooplankton communities graze at similar rates in low productivity lakes. Can. J. Fish. Aquat. Sci. 55: 414 422, doi:10.1139/cjfas-55-2-414

Dadswell, M. J. 1974. Distribution, ecology, and postglacial dispersal of certain crustaceans and fishes in eastern North America. Publication in Zoology No. 11. National Museum of Natural Sciences.

Fox, J. 2006. Structural equation modeling with the sem package in R. Struct. Eq. Model. 13: 465-486, doi:10.1207/ s15328007sem1303_7

Grace, J. B. 2006. Structural equation modeling and natural systems. Cambridge Univ. Press.

Graham, M. H. 2003. Confronting multicollinearity in ecological multiple regression. Ecology 84: 2809-2815, doi:10.1890/ 02-3114

Hovius, J. T., B. E. Beisner, and K. S. McCann. 2006. Epilimnetic rotifer community responses to Bythotrephes longimanus invasion in Canadian Shield lakes. Limnol. Oceanogr. 51: 1004-1012, doi:10.4319/lo.2006.51.2.1004

$\longrightarrow,-,-$ AND N. D. YAN. 2007. Indirect food web effects of Bythotrephes invasion: Responses by the rotifer Conochilus in Harp Lake, Canada. Biol. Invasions 9: 233-243, doi:10.1007/s10530-006-9028-2

JePPESEN, E., AND others. 2003. The impact of nutrient state and lake depth on top-down control in the pelagic zone of lakes: A study of 466 lakes from the temperate zone to the Arctic. Ecosystems 6: 313-325, doi:10.1007/s10021-002-0145-1

JEZIORSKI, A., AND OTHERS. 2008. The widespread threat of calcium decline in fresh waters. Science 322: 1374-1377, doi:10.1126/ science. 1164949

Johnson, P. T. J., J. D. Olden, And M. J. Vander Zanden. 2008. Dam invaders: Impoundments facilitate biological invasions into freshwaters. Front. Ecol. Environ. 6: 357-363, doi:10.1890/070156

Keller, W. 2009. Limnology in northeastern Ontario: From acidification to multiple stressors. Can. J. Fish. Aquat. Sci. 66: 1189-1198, doi:10.1139/F09-080

_- AND M. Conlon. 1994. Crustacean zooplankton communities and lake morphometry in Precambrian Shield lakes. Can. J. Fish. Aquat. Sci. 51: 2424-2434, doi:10.1139/ f94-242

KLINE, R. B. 2005. Principles and practice of structural equation modeling. Guilford Press.

Legendre, P., AND E. D. Gallagher. 2001. Ecologically meaningful transformations for ordination of species data. Oecologia 129: 271-280, doi:10.1007/s004420100716

LeHMAn, J. T. 1988. Algal biomass unaltered by food web changes in Lake Michigan. Nature 332: 537-538, doi:10.1038/332537a0

Leibold, M. A., J. M. Chase, J. B. Shurin, And A. L. Downing. 1997. Species turnover and the regulation of trophic structure. Ann. Rev. Ecol. Syst. 28: 467-494, doi:10.1146/annurev.ecolsys.28.1.467

Macisaac, H. J., H. A. M. Ketelaars, I. A. Grigorovich, C. W. Ramcharan, And N. D. Yan. 2000. Modeling Bythotrephes longimanus invasions in the Great Lakes basin based on its European distribution. Arch. Hydrobiol. 149: 1-21.

McCann, K. S., A. Hastings, and D. R. Strong. 1998. Trophic cascades and trophic trickles in pelagic food webs. Proc. R. Soc. Lon. B 265: 205-209, doi:10.1098/rspb.1998.0283

McQueen, D. J., J. R. Post, And E. L. Mills. 1986. Trophic relationships in freshwater pelagic ecosystems. Can. J. Fish. Aquat. Sci. 43: 1571-1581, doi:10.1139/f86-195

Minns, C. K., J. E. Moore, D. W. Schindler, And M. L. Jones. 1990. Assessing the potential extent of damage to inland lakes in eastern Canada due to acidic deposition. III. Predicted impacts on species richness in seven groups of aquatic biota. Can. J. Fish. Aquat. Sci. 47: 821-830, doi:10.1139/f90-095 
Molot, L., AND P. J. Dillon. 1996. Storage of terrestrial carbon in boreal lake sediments and evasion to the atmosphere. Glob. Biogeochem. Cy. 10: 483-492, doi:10.1029/96GB01666

Muirhead, J. R., And H. J. MacIsaac. 2005. Development of inland lakes as hubs in an invasion network. J. Appl. Ecol. 42: 80-90, doi:10.1111/j.1365-2664.2004.00988.x

Noonburg, E. G., And J. E. Byers. 2005. More harm than good: When invader vulnerability to predators enhances impact on native species. Ecology 86: 2555-2560, doi:10.1890/05-0143

Ontario Federation of Anglers and Hunters. 2010. Ontario Federation of Anglers and Hunters Database [Internet]. Peterborough, Ontario: Ontario Federation of Anglers and Hunters [accessed September 2009]. Available from http:// www.invadingspecies.com/Invaders.cfm?A $=$ Page \&PID $=2$

Ontario Ministry of the Environment. 2003. Approved routine methods reports E3042, 3422, 3249, 3036, 3147, 3424, 3024, 3386. Ontario Ministry of the Environment, Laboratory Services Branch, Quality Management Unit.

Pace, M. L., J. J. Cole, S. R. Carpenter, and J. F. Kitchell. 1999. Trophic cascade revealed in diverse ecosystems. Trends Ecol. Evol. 14: 483-488, doi:10.1016/S0169-5347(99)01723-1

Pangle, K. L., S. D. Peacor, and O. E. Johannsson. 2007. Large nonlethal effects of an invasive invertebrate predator on zooplankton population growth rate. Ecology 88: 402-412, doi:10.1890/06-0768

Paterson, A. M., J. G. Winter, K. H. Nicholls, B. J. Clark, C. W. Ramcharan, N. D. Yan, and K. M. Somers. 2008. Longterm changes in phytoplankton composition in seven Canadian Shield lakes in response to multiple anthropogenic stressors. Can. J. Fish. Aquat. Sci. 65: 846-861, doi:10.1139/F08-022

Peres-Neto, P. R., P. Legendre, S. Dray, and D. Borcard. 2006. Variation partitioning of species data matrices: Estimation and comparison of fractions. Ecology 87: 2614-2625, doi:10.1890/0012-9658(2006)87[2614:VPOSDM]2.0.CO;2

Pérez-Fuentetaja, A., D. J. McQueen, N. D. Yan, and P. J. DiLlon. 2000. Zooplankton biomass rarely improves predictions of chlorophyll concentration in Canadian Shield lakes that vary in pH. Aquat. Ecol. 34: 127-136, doi:10.1023/ A:1009934506481

Pinel-Alloul, B., G. Méthot, G. Verreault, and Y. Vigneault. 1990. Zooplankton species associations in Quebec lakes: Variation with abiotic factors, including natural and anthropogenic acidification. Can. J. Fish. Aquat. Sci. 47: 110-121, doi:10.1139/f90-011

— environmental components of freshwater zooplankton structure. Ecoscience 2: 1-19.

R Development Core Team. 2010. R: A language and environment for statistical computing [Internet]. Vienna, Austria: R Foundation for Statistical Computing [accessed April 2010]. Available from http://www.r-project.org/index.html

SAlo, P., E. KorpimäKI, P. B. BanKs, M. Nordström, and C. R. Dickman. 2007. Alien predators are more dangerous than native predators to prey populations. Proc. Roy. Soc. B 274: 1237-1243, doi:10.1098/rspb.2006.0444

Schulz, K. L., And P. M. Yurista. 1995. Diet composition from allozyme analysis in the predatory cladoceran Bythotrephes cederstroemi. Limnol. Oceanogr. 40: 821-826, doi:10.4319/ lo.1995.40.4.0821

SHURIN, J. B., AND OTHERS. 2002. A cross-ecosystem comparison of the strength of trophic cascades. Ecol. Lett. 5: 785-791, doi:10.1046/j.1461-0248.2002.00381.x

Shuter, B. J., AND D. M. MAson. 2001. Exotic invertebrates, food-web disruption, and lost fish production: Understanding impacts of dreissenid and cladoceran invaders on lower-lakes fish communities and forecasting invasion impacts on upper-lakes fish communities [Internet]. Ann Arbor, Michigan: Board of Technical Experts, Great Lakes Fishery Commission [accessed June 2010]. Available from http://www.glfc.org/staff/fweb_whitepaper. pdf

Sprules, W. G. 1975. Midsummer crustacean zooplankton communities in acid-stressed lakes. J. Fish. Res. Board Can. 32: 389-395.

Strayer, D. L., M. L. Pace, N. F. Caraco, J. J. Cole, and S. E. G. FINDLAY. 2008. Hydrology and grazing jointly control a largeriver food web. Ecology 89: 12-18, doi:10.1890/07-0979.1

Strecker, A. L., And S. E. Arnott. 2005. Impact of Bythotrephes invasion on zooplankton communities in acid-damaged and recovered lakes on the Boreal Shield. Can. J. Fish. Aquat. Sci. 62: 2450-2462, doi:10.1139/f05-152

, AND - 2008. Invasive predator, Bythotrephes, has varied effects on ecosystem function in freshwater lakes. Ecosystems 11: 490-503, doi:10.1007/s10021-008-9137-0

,-- N. D. YAN, AND R. GiRARD. 2006. Variation in the response of crustacean zooplankton species richness and composition to the invasive predator Bythotrephes longimanus. Can. J. Fish. Aquat. Sci. 63: 2126-2136, doi:10.1139/F06-105

TER BraAk, C. J. F., AND P. ŠMilauer. 2002. CANOCO version 4.5 [Internet]. Wageningen, The Netherlands: Biometris-Plant Research International. Available from http://www.pri.wur. $\mathrm{nl} / \mathrm{uk} /$ products/canoco/

Vander Zanden, M. J., K. A. Wilson, J. M. Casselman, and N. D. YAN. 2003. Species introductions and their impacts in North American Shield lakes, p. 239-263. In J. Gunn, R. Steedman, and R. Ryder [eds.], Boreal Shield watersheds: Lake Trout ecosystems in a changing environment. CRC Press.

Wahlström, E., And E. Westman. 1999. Planktivory by the predacious cladoceran Bythotrephes longimanus: Effects on zooplankton size structure and abundance. Can. J. Fish. Aquat. Sci. 56: 1865-1872, doi:10.1139/cjfas-56-10-1865

Watson, S. B., E. McCauley, and J. A. Downing. 1997. Patterns in phytoplankton taxonomic composition across temperate lakes of differing nutrient status. Limnol. Oceanogr. 42: 487-495, doi:10.4319/1o.1997.42.3.0487

Weisz, E. J., AND N. D. YAN. 2010. Relative value of limnological, geographic and human use variables as predictors of the presence of Bythotrephes longimanus in Canadian Shield lakes. Can. J. Fish. Aquat. Sci. 67: 462-472, doi:10.1139/F09-197

Wetzel, R. G. 2001. Limnology: Lake and river ecosystems, 3rd ed. Academic Press.

Yan, N. D., R. E. Girard, and S. Boudreau. 2002. An introduced invertebrate predator (Bythotrephes) reduces zooplankton species richness. Ecol. Lett. 5: 481-485, doi:10.1046/j.1461-0248.2002.00348.x

- AND T. W. PAwson. 1997. Changes in the crustacean zooplankton community of Harp Lake, Canada, following invasion by Bythotrephes cederstroemi. Freshw. Biol. 37: 409-425, doi:10.1046/j.1365-2427.1997.00172.x

— Dorset, Ontario, lakes: The probable interactive effects of changes in $\mathrm{pH}$, total phosphorus, dissolved organic carbon, and predators. Can. J. Fish. Aquat. Sci. 65: 862-877, doi:10.1139/F07-197

Young, J. D., AND N. D. YAn. 2008. Modification of the diel vertical migration of Bythotrephes longimanus by the coldwater planktivore, Coregonus artedi. Freshw. Biol. 53: 981-995, doi:10.1111/j.1365-2427.2008.01954.x

Associate editor: Luc De Meester

Received: 02 February 2010

Accepted: 19 September 2010

Amended: 06 October 2010 